\title{
LEGITIMIDADE DAS ORGANIZAÇÕES NÃO-GOVERNAMENTAIS PARA PROPOSITURA DE AÇÃO POP̉ULAR EM MATÉRIA AMBIENTAL
}

\section{NON-GOVERNMENTAL ORGANIZATION'S LEGITIMACY FOR PROPOSITION OF POPULAR LEGAL ACTION IN ENVIRONMENTAL SUBJECT}

\author{
Juliana Campos de Oliveira" \\ Rafaela Campos de Oliveira*"
}

\begin{abstract}
Resumo: $O$ desenvolvimento tecnológico ocorrido no mundo, desencadeado pela Revolução Industrial, ocasionou a degradação ambiental em proporções preocupantes. A princípio, sob influência do paradigma antropocêntrico, não era dispensada a devida atenção ao problema da degradação ambiental. Entretanto, com a evolução de pesquisas neste âmbito, foi se desenvolvendo o paradigma biocêntrico, que considerava o ambiente como um todo orgânico, no qual os seres humanos são componentes indissociáveis. A partir de então, Constituições de diversos Estados passaram a tutelar o meio ambiente de forma mais eficaz, sendo incluído o acesso à justiça ambiental. Este artigo objetiva, deste modo, propor a inclusão das ONG’s como legitimadas ativas para propor Ação Popular Ambiental.
\end{abstract}

Palavras-chave: Ação popular. Legitimidade ativa. ONG’s. Efetividade. Tutela ambiental.

\begin{abstract}
The technological-industrial development occurred in the world unleashed by the Industrial Revolution, causing environmental degradation in worrying proportions. At first, under the influence of the anthropocentric paradigm, the problem of environmental degradation was not given due attention. However, with the development of research in this area, the biocentric paradigm has been developed, which considered the environment as an organic whole in which humans are inseparable components. Since then, the Constitutions of several countries has begun to protect the environment more effectively, including access to environmental justice. This article proposes the inclusion of NGO's as active legitimates to Popular Environmental Action.
\end{abstract}

Key-words: Popular action. Active legitimacy. NGO’S. Effectiveness. Guardianship environmental.

Mestranda em Direito Público pela Universidade Federal da Bahia. Graduada em Direito pela UEPB. Email: julipbp@yahoo.com.br.

Aluna da Especialização em Direito Ambiental da Fundação Faculdade de Direito da Universidade Federal da Bahia. Graduada em Direito pela UEPB. Email: rafinhabmcampos@yahoo.com.br 


\section{INTRODUÇÃO}

No inicio do período de urbanização e crescimento industrial, em termos mundiais, sobretudo no limiar do século XIX, quando se estabeleceu o apogeu da Revolução Industrial, pouca ou nenhuma atenção era conferida à proteção do meio ambiente natural.

Seguindo o paradigma antropocêntrico, o ser humano se considerava em patamar superior e independente da natureza.

Entretanto, o avanço nas pesquisas e a constatação de que a degradação do meio ambiente afeta diretamente os seres vivos, incluindo os seres humanos, deu ensejo ao denominado paradigma biocêntrico. $O$ desenvolvimento do paradigma biocêntrico em detrimento do paradigma antropocêntrico foi adquirindo mais força, o que proporcionou o desenvolvimento da ideia de que o meio ambiente é um bem autônomo e que precisa ser tutelado não apenas em virtude da qualidade de vida do ser humano, mas também enquanto bem jurídico possuidor de autonomia e necessidades próprias.

A partir de então as Constituições de diversos países passaram a tutelar o meio ambiente enquanto direito fundamental e instrumentos processuais passaram a ser utilizados para sua proteção.

No Brasil, um desses instrumentos jurídicos processuais é a Ação Popular. Apesar de ser do entendimento geral que a Ação Popular tem como legitimados ativos os cidadãos, pretende-se, através deste artigo, defender que as ONG's defensoras do meio ambiente ecologicamente equilibrado possam ser legitimadas para propor Ação Popular.

\section{PROTEÇÃO AMBIENTAL}

O crescimento urbano, econômico e desorganizado que se estabeleceu a partir da Revolução Industrial, sobretudo no século XIX, trouxe inúmeros avanços tecnológicos mas, em contrapartida, destruição ambiental. Neste período foram tecidos os primeiros fios do capitalismo moderno.

Gordilho (2009b, p. 26) considera que:

O capitalismo desorganizado se caracteriza pela pujança sem precedentes do mercado, que extravasando o domínio econômico, coloniza tanto o princípio do Estado como o da comunidade, neutralizando a capacidade de regulação nacional da economia, acentuando as diferenças entre o norte e o sul e comprometendo o equilíbrio da biosfera.

Imersos neste contexto, os cientistas possuíam um posicionamento antropocêntrico, em que o homem era o ator principal das relações sociais, 
sendo o meio ambiente natural considerado apenas como fornecedor de recursos para o progresso da humanidade. O ser humano era visto de forma apartada da natureza e em situação de superioridade.

Capra (2006, p. 25) defende que nesse período existia uma "ecologia rasa" e esclarece que "a ecologia rasa é antropocêntrica, ou centralizada no ser humano. Ele vê os seres humanos como situados acima ou fora na natureza, como a fonte de todos os valores, e atribui apenas um valor instrumental, ou de 'uso', à natureza".

Com o passar dos anos, estudos passam a demonstrar que os recursos naturais são limitados e que os seres humanos são parte integrante da natureza, dela dependendo sua sobrevivência. De um paradigma antropocêntrico, foram surgindo estudiosos defensores do paradigma biocêntrico, sobretudo na segunda metade do século XX, por volta da década de 70, quando ocorreu a Conferência das Nações Unidas sobre o Ambiente Humano, em Estocolmo, no ano de 1972.

Em outra obra, Gordilho (2009a, p. 92) salienta que "existe uma tendência mundial de superação do antropocentrismo clássico, e os elementos naturais cada vez mais têm sido objeto de consideração moral, pois muitas vezes são protegidos em detrimento dos interesses humanos imediatos".

Em complementação ao pensamento de Gordilho, Capra (2006, p. 25) afirmam que:

O paradigma que está agora retrocedendo dominou a nossa cultura por várias centenas de anos, durante as quais modelou nossa moderna sociedade ocidental e influenciou significativamente o restante do mundo. Esse paradigma consiste em várias idéias e valores entrincheirados, entre os quais a visão do universo como um sistema mecânico composto de blocos de construção elementares, a visão do corpo humano como uma máquina, a visão da vida em sociedade como uma luta competitiva pela existência, a crença no progresso material ilimitado, a ser obtido por intermédio de crescimento econômico e tecnológico.

O paradigma biocêntrico proporciona o estudo do meio ambiente natural como um todo orgânico que possui autonomia e interesses próprios. A preocupação com a proteção ambiental tornou-se fundamental, passando-se a pleitear a colaboração de todos na defesa dos problemas relativos à degradação ambiental.

Ainda em referência a Capra (2006, p. 25), tem-se que:

O novo paradigma pode ser chamado de uma visão de mundo holística, que concebe o mundo como um todo integrado, e não como uma coleção de partes dissociadas. Pode também ser denominado visão ecológica, se o termo 'ecológica' for empregado num sentido muito mais amplo e mais profundo que o usual. 
A percepção ecológica profunda reconhece a interdependência fundamental de todos os fenômenos, e o fato de que, enquanto indivíduos e sociedades, estamos todos encaixados nos processos cíclicos da natureza.

Nesse processo evolutivo dos esforços relacionados à proteção do meio ambiente, as Constituições de diversos Estados passaram a inserir a tutela ambiental como direito fundamental, de caráter transindividual, consubstanciando-se em direito e dever de todos. Como exemplo tem-se a Constituição de Portugal, de 1976, a Constituição da Espanha de 1978 e a Constituição brasileira de 1988.

Neste sentido, Benjamin (2007, p. 61-2) admite que:

Olhando em volta, é seguro dizer que a constitucionalização do ambiente é uma irreversível tendência internacional, que coincide com o surgimento e consolidação do Direito Ambiental. [...] Nessa evolução acelerada, numa primeira onda de constitucionalização ambiental, sob a direta influência da Declaração de Estocolmo de 1972, vieram as novas Constituições dos países europeus que se libertavam de regimes ditatoriais, como a Grécia (1975), Portugal (1976) e Espanha (1978). Posteriormente, num segundo grupo, ainda em período fortemente marcado pelos padrões e linguagem de Estocolmo, foi a vez de países como o Brasil. Finalmente, após a Rio-92, outras Constituições foram promulgadas ou reformadas incorporando, expressamente, novas concepções, como a de desenvolvimento sustentável, biodiversidade e precaução. O exemplo mais recente deste grupo é a França, que em 2005 adotou sua Charte de I'environnement.

Relativamente ao Brasil, tem-se que a Constituição de 1988 recepcionou no caput do seu artigo 225 o direito fundamental ao meio ambiente ecologicamente equilibrado:

Art. 225. Todos têm direito ao meio ambiente ecologicamente equilibrado, bem de uso comum do povo e essencial à sadia qualidade de vida, impondo-se ao Poder Público e à coletividade o dever de defendê-lo e preservá-lo para as presentes e futuras gerações.

Diante da nova caracterização do direito ambiental como um bem autônomo e carente de tutela, alguns mecanismos de garantia de proteção foram adotados no Brasil, entre os quais a Ação Popular.

\section{LEGIMIDADOS E OBRIGADOS À PROTEÇÃO AMBIENTAL}

No âmbito do Brasil tem-se que, de acordo com o caput do artigo 225, o direito ao meio ambiente ecologicamente equilibrado é direito de todos, sendo imposto não apenas ao Ministério Público, mas à toda coletividade o dever de proteção, visando tanto as presentes quanto as futuras gerações e demonstrando um caráter intergeracional. 
A expressão "todos" trazida naquele dispositivo constitucional leva à interpretação de que deve haver, conforme explica Leite e Ayala, seguindo raciocínio adotado por Canotilho, uma "democracia ambiental". Neste sentido é indispensável que haja uma unidade entre cidadãos, Estado e meio ambiente.

Segundo Leite e Ayala (2002, p. 31):

Não há com negar que, para se discutir, impor condutas, buscar soluções e consensos que levem à proteção ambiental, é necessária a participação dos mais diversos atores (grupos de cidadãos, ONG’s, cientistas, corporações industriais e muitos outros) e, por outro lado, um Estado democrático na perspectiva ambiental, detentor de um aparato legislativo apto a realizar essa tarefa. Trata-se, de fato, de o Estado passar a incentivar a emergência de um pluralismo jurídico comunitário participativo no viés ambiental, consubstanciado em modelo democrático, que privilegie a participação dos sujeitos sociais na regulamentação das instituições-chave da sociedade.

É importante considerar ainda que, devido ao fato de que o meio ambiente não conhece fronteiras, a sua proteção adquire um caráter interterritorial. Atividades realizadas em um país podem prejudicar o meio ambiente natural de outro(s) país(es), gerando um dano ambiental em cadeia que pode trazer graves conseqüências para o integridade natural de todo o planeta. Para Leite e Ayala:

No caso da proteção ao meio ambiente os obstáculos são ainda maiores, pois suas exigências dizem respeito à uma dimensão planetária, ou seja, demandam instrumentos em nível internacional ou intercomunitário e não isoladamente no interior do Estado de direito. Ao que parece, uma internacionalização das políticas de crescimento poderia ser um instrumento para deter a perda do patrimônio ambiental (2002, p. 23).

Sendo assim, é possível atribuir o dever de proteção ambiental a todos os indivíduos em âmbito mundial, sem distinção de nacionalidade ou território, tendo em vista a tutela do meio ambiente em nível internacional.

\section{AÇÃO POPULAR COMO INSTRUMENTO DE PROTEÇÃO AMBIENTAL}

Em matéria ambiental é importante salientar que antes serem utilizados mecanismos que visem a reparação de danos, há uma preferência no sentido de se adotar medidas de prevenção e precaução. Neste sentido, Leite e Ayala admitem que "os meios judiciais são, de fato, o último recurso contra a ameaça e a degradação ambiental, pois antes destes os mecanismos de prevenção e precaução têm papel de destaque na política ambiental” (2002, p. 36).

Mas considerando-se que o risco de ocorrência de danos ambientais é constante, necessário se faz que existam instrumentos capazes da assegurar 
juridicamente que prejuízos ambientais sejam detectados e reparados na medida do possível.

Mirra (1994, p. 18) esclarece que "realmente, por mais perfeitas que sejam as normas de controle e a sua aplicação, o dano ambiental ainda assim pode ocorrer, atado que está à inevitabilidade de acidentes”.

Em se tratando do acesso à justiça em matéria ambiental no Brasil, tem-se que além da Ação Civil Pública pode ser proposta a Ação Popular.

A Constituição Federal de 1988 estabeleceu, em seu artigo 5º, inciso LXXIII que:

Qualquer cidadão é parte legítima para propor ação popular que vise a anular ato lesivo ao patrimônio público ou de entidade de que o Estado participe, à moralidade administrativa, ao meio ambiente e ao patrimônio histórico e cultural, ficando o autor, salvo comprovada má-fé, isento de custas judiciais e do ônus da sucumbência.

Este dispositivo constitucional permitiu que a Ação Popular pudesse ser proposta também em caso de ato lesivo ao meio ambiente. Entretanto, não houve uma modificação da Lei no 4.717, de 29 de junho de 1965, que regula a Ação Popular, no sentido de adequá-la a uma aplicação mais eficaz em matéria ambiental. Isto porque no âmbito do meio ambiente natural, é difícil mensurar a dimensão do dano, atribuir valor à natureza. Sendo assim, a inclusão das questões ambientais no âmbito de proteção da Ação Popular configurou um avanço, entretanto a sua utilização nos moldes da Lei no 4.717/65 limitou a tutela efetiva do meio ambiente em alguns casos. Um exemplo é o âmbito restrito de legitimados ativos para propor esta ação.

De acordo com o artigo $1^{\circ}$ da Lei de Ação Popular, qualquer cidadão pode ser legitimado ativo para realizar sua proposição:

Qualquer cidadão será parte legítima para pleitear a anulação ou a declaração de nulidade de atos lesivos ao patrimônio da União, do Distrito Federal, dos Estados, dos Municípios, de entidades autárquicas, de sociedades de economia mista, de sociedades mútuas de seguro nas quais a União represente os segurados ausentes, de empresas públicas, de serviços sociais autônomos, de instituições ou fundações para cuja criação ou custeio o tesouro público haja concorrido ou concorra com mais de cinqüenta por cento do patrimônio ou da receita ânua, de empresas incorporadas ao patrimônio da União, do Distrito Federal, dos Estados e dos Municípios, e de quaisquer pessoas jurídicas ou entidades subvencionadas pelos cofres públicos.

Por cidadão entendem-se os indivíduos dotados de nacionalidade brasileira e de poderes políticos, uma vez que o $§ 3^{\circ}$ do artigo $1^{\circ}$, supracitado, esclarece 
que a prova de cidadania será feita através do título de eleitor, tal como por se verificar: "Art. $1^{\circ}[\ldots], \S 3$ : : A prova da cidadania, para ingresso em juízo, será feita com o título eleitoral, ou com documento que a ele corresponda."

A Ação Popular é considerada o primeiro instrumento processual que possui claramente como escopo a proteção e defesa dos interesses da coletividade, porque apesar de ser impetrada por um particular, possui o objetivo de defender interesses difusos.

\section{AS ORGANIZAÇÕES NÃO-GOVERNAMENTAIS COMO LEGITIMADAS PARA PROPOR AÇÃO POPULAR EM MATÉRIA AMBIENTAL}

Atribuindo legitimidade ativa apenas aos cidadãos, a Lei da Ação Popular adquire caráter restritivo em matéria ambiental. É possível fazer esta afirmação devido a inúmeros fatores.

Um deles é que em geral, o pólo passivo da ação é composto por grandes empresas ou até pelo próprio Estado. Nesse tipo de situação o cidadão, sozinho, se torna frágil diante da grandeza econômica e de poder do representante do pólo passivo. Seguindo esta linha de raciocínio, Milaré (1993, p. 265) considera que:

O particular ofendido não se apresenta, normalmente, em condições de assumir e desenvolver ação eficaz contra o agressor, quase sempre poderosos grupos econômicos, quando não o próprio Estado. Ademais, o dano causado a cada indivíduo normalmente será pequeno, dificilmente apreciável ou determinável. Assim, o particular fatalmente se sentirá desestimulado a empreender a defesa do ambiente, ou de bater às portas do Judiciário [...]. Tudo corre para desencorajá-lo: o vulto das despesas, a complexidade das questões, a carência de conhecimentos técnicos, a força política e econômica dos adversários. Outro fator é que, via de regra, os cidadãos não tem conhecimento, dimensão da sua responsabilidade em relação às questões ambientais. A falta de informação, de uma educação no âmbito da preservação do meio ambiente, torna a sociedade carente de atitudes individuais voltadas para proteção da natureza.

Neste sentido, considera-se que seria necessária uma adequação da Ação Popular para a tutela mais eficaz do meio ambiente, e para justificar a necessidade de adequação da legislação em prol da tutela do meio ambiente, importante citar Leite e Ayala, para quem:

Não é possível construir-se um Estado democrático do ambiente como Estado de direito sem a garantia do direito fundamental de amplo acesso à justiça e ao devido processo legal para as questões ambientais. Só com uma transformação profunda em várias áreas do direito, principalmente nos campos do direito civil e processo civil, de índole individualista, viabilizar-se-á a tutela jurisdicional 
ambiental. O Direito do Ambiente tem uma dimensão horizontal e exige uma readaptação de outras áreas do saber jurídico, para se garantir o acesso adequado à justiça. A sociedade atual exige que os interesses ou direitos ambientais sejam palco de discussão na via judiciária, pois essa abertura resultará no exercício da cidadania e, como conseqüência, na conscientização ambiental (2002, p. 36).

Uma modificação importante na Lei da Ação Ambiental seria a ampliação do rol de legitimados ativos, abrangendo além dos cidadãos de forma individualizada, os cidadãos de forma organizada, enquanto organizações nãogovernamentais (ONG's). Isto porque, via de regra, os integrantes de ONG's trabalham de forma direta na proteção dos interesses que defendem, neste caso, interesses de cunho ambiental. As ONG's ambientalistas são compostas por cidadãos que possuem maior nível de informação e consciência de sua responsabilidade perante a preservação do meio ambiente.

Esta discussão remete à súmula 365 do Supremo Tribunal Federal que estabelece: "Pessoa jurídica não tem legitimidade para propor ação popular".

Partindo-se do pressuposto de que as ONG's são consideradas entidades com personalidade jurídica sem fins lucrativos, fazendo parte do chamado "terceiro setor”, que de acordo com o que dispõe o Promotor de Justiça Tomás de Aquino Resende (2010, p. 1) configura-se como sendo:

Aquele que congrega as organizações que, embora prestem serviços públicos, produzam e comercializem bens e serviços, não são estatais, nem visam lucro financeiro com os empreendimentos efetivados, estando incluídas aqui, portanto, as associações, sociedades sem fins lucrativos e fundações.

É possível afirmar, deste modo, que se faz mister a modificação da Lei $\mathrm{n}^{\underline{0}}$ 4.717/65 no sentido de ampliar o rol de legitimados ativos para propositura de ação popular em matéria ambiental. Desta forma, de acordo com Oliveira Júnior, estabelecendo que "a súmula vinculante perderá a eficácia se a norma que por ela foi interpretada vier a ser modificada ou alterada pelo Poder Legislativo" (2005, p. 1), tornaria ineficaz a súmula 365, possibilitando às ONG’s interpor Ação Popular em matéria ambiental.

É importante salientar que situação semelhante já é adotada na legislação de Portugal, a qual é considerada pioneira e atual em termos de proteção ambiental. Leite e Ayala (2002, p. 37) salientam que:

A experiência da class action dos Estados Unidos da América, a ação civil pública e a ação popular brasileiras, e a ação popular portuguesa são instrumentos mais atuais da tutela jurisdicional ambiental e têm incentivado os operadores jurídicos a discutir e refletir sobre as questões emergentes. A grande e, talvez, a 
maior dificuldade em construir um Estado ambiental é transformá-lo em um Estado de justiça ambiental.

No Brasil existem doutrinadores que defendem a ampliação da legitimidade ativa para propositura de Ação Popular, entre eles Celso Antônio Pacheco Fiorillo.

No que concerne à questão da justiça ambiental é importante destacar o pensamento de Cavedon e Vieira (2006, p. 13) que consideram:

A possibilidade formal de acesso à justiça em matéria ambiental através da disponibilização de instrumentos processuais de tutela coletiva não garante a sua efetiva utilização pelos titulares do bem ambiental. É preciso que os sujeitos de direitos ambientais tenham acesso à informação e estejam aptos a identificar as agressões ao meio ambiente como lesão a direito seu. Devem dispor de meios, materiais e informacionais, para fazer chegar à esfera jurídico-institucional os conflitos ambientais [...]. Verifica-se uma relação intrínseca entre justiça ambiental e acesso à justiça, já que os grupos que arcam com uma carga desproporcional de custos e riscos ambientais pelas suas condições socioeconômicas, racial, informacional e de poder, são também, por óbvio, os que enfrentam maiores barreiras de acesso.

Posteriormente, refletindo acerca do acesso à justiça de forma democrática, afirmam os autores que:

Democratizar o acesso à justiça em matéria ambiental significa criar possibilidades para que os vitimados pela desigualdade e exclusão ambiental possam representar adequadamente o interesse ambiental lesado, com a garantia de ampla participação nos processos decisórios, dispondo de instrumental informacional para influir na conformação das decisões referentes aos conflitos jurídico-ambientais. Significa dar iguais possibilidades de inserir tais conflitos na esfera jurídico-institucional, o que pode se configurar em um meio eficaz de empoderamento dos grupos atingidos por situações de injustiça ambiental. Assim é que a garantia do amplo Acesso à justiça pode possibilitar a inserção dos excluídos ambientais, pela disponibilização de instrumentos e espaços democráticos de gestão ambiental e de decisão de conflitos, capazes de restabelecer a proporcionalidade na distribuição dos custos e benefícios ambientais (Cavedon; Vieira, 2006, p. 15).

Para completar esta discussão, mas longe de finalizá-la, uma vez que necessita de maiores debates e discussões, indispensável salientar as considerações abordadas por Canotilho (1995, p. 35) sobre o tema da injustiça ambiental. Entende o autor, que a discriminação ambiental ou injustiça ambiental _ entendida como qualquer decisão, prática administrativa ou atividade referente à tutela ambiental que venha a onerar, em termos discriminatórios, indivíduos, grupos ou comunidades em virtude de raça, situação econômica ou localização geográfica - deve ser amplamente combatida por todos. 
Entende-se, deste modo, que a ampliação dos legitimados ativos para propor a Ação Popular em defesa do meio ambiente garante o maior acesso à justiça, além de tornar a tutela do meio ambiente natural mais ampla.

\section{CONCLUSÃO}

Diante o exposto, conclui-se que por ser o meio ambiente natural um bem dotado de peculiaridades que o configuram como carente de tutela especial necessita, por sua vez, que os instrumentos utilizados para sua proteção possuam características diferenciadas.

A proteção do meio ambiente é considerada transindividual e visa tutelar o meio ambiente enquanto bem jurídico autônomo e enquanto necessário à sobrevivência dos seres vivos da presente e das futuras gerações.

O que se objetiva, sobretudo, é a precaução e prevenção de danos ambientais. Mas ocorrendo tais danos, instrumentos processuais são disponibilizados para sua reparação. Entre eles, tem-se, no Brasil, a Ação Popular.

É notório, entretanto, que a Ação Popular, em matéria ambiental, sofre algumas limitações, devido ao fato de não ter sido adaptada às características particulares inerentes ao meio ambiente natural.

A mais importante dessas limitações é o âmbito restritivo dos legitimados ativos para propor a Ação Popular. Isto porque, apesar de ser direcionada a todos os cidadãos, no que concerne à proteção do meio ambiente, o que se tem é que os cidadãos, considerados de forma isolada, são frágeis e muitas vezes desconhecedores de seu papel perante as questões ambientais.

Entende-se que possibilitando a entidades tais como as ONG's ambientalistas propor Ação Popular em defesa do meio ambiente, o acesso à justiça neste caso seria mais eficaz, o que tornaria a tutela do meio ambiente natural mais ampla.

Defende-se ainda a flexibilização dos legitimados ativos para propor Ação Popular uma vez que este instrumento processual é mais acessível, menos oneroso que a Ação Civil Pública.

Além disso, não há razão para a recusa na ampliação dos legitimados ativos proponentes da Ação Popular, uma vez que além de pretender trazer benefícios à tutela do meio ambiente, tal modificação não irá configurar em prejuízos para os demais bens tutelados por este instrumento.

\section{REFERÊNCIAS}

BENJAMIN, Antônio Herman de Vasconcelos e. Direito constitucional ambiental brasileiro. In: CANOTILHO, José Joaquim Gomes; LEITE, José Rubens Morato (Org.). Direito constitucional ambiental brasileiro. São Paulo: Saraiva, 2007. 
BRASIL. Constituição da República Federativa do Brasil de 1988. Disponível em: 〈http://www.presidenciadarepublica.gov.br>. Acesso em: 31 mar. 2010.

. Lei $n^{-}$4.717/65. Disponível em: <http:www.presidenciadarepublica. gov.br>. Acesso em: 31 mar. 2010.

CANOTILHO, Jose J. Gomes. Direito público do ambiente. Coimbra: Faculdade de Direito de Coimbra, 1995.

CAPRA, Fritjof. A teia da vida: uma nova compreensão científica dos sistemas vivos. Tradução: Newton Roberval Eichemberg. São Paulo: Cultrix, 2006.

CAVEDON, Fernanda de Salles; VIEIRA, Ricardo Stanziola. Acesso à justiça ambiental: um novo enfoque do acesso à justiça a partir da sua aproximação com a teoria da justiça ambiental. Disponível em: <http://www.conpedi.org/ manaus>. Acesso em: 5 abr. 2010.

GORDILHO, Heron José de Santana. Abolicionismo animal. Salvador: Evolução, 2009.

. Direito ambiental pós-moderno. Salvador: Juruá, 2009b.

LEITE, José Rubens Morato; AYALA, Patryck de Araújo. Direito ambiental na sociedade de risco. Rio de Janeiro: Forense, 2002.

MILARÉ, Edis. Dano ambiental, prevenção, reparação e repressão. Antônio Herman V. Benjamin (Coord.). São Paulo: Editora Revista dos Tribunais, 1993.

MIRRA, Álvaro Luiz Valery. Fundamentos do direito ambiental no Brasil. Revista dos Tribunais, São Paulo, v. 83, n. 706, p. 7-29, ago. 1994.

OLIVEIRA JUNIOR, Roney. A solidez da súmula vinculante e a fragilidade da súmula impeditiva de recursos . Jus Navigandi, Teresina, ano 9, n. 575, 2 fev. 2005. Disponível em: 〈http://jus2.uol.com.br/doutrina/texto.asp?id=6271〉. Acesso em: 4 abr. 2010.

RESENDE, Tomás Aquino. Terceiro setor, ONG's e institutos. Disponível em: $<$ http://www.fundata.org.br/Artigos\%20\%20Cefeis/TERCEIRO\%20SETOR,\%20 ongs.htm>. Acesso em: 6 abr. 2010.

Artigo recebido em 19/04/10 e aprovado para publicação em 20/09/10 
